\title{
On the origin of multidecadal to centennial Greenland temperature anomalies over the past $800 \mathrm{yr}$
}

\author{
T. Kobashi ${ }^{1,2}$, D. T. Shindell ${ }^{3}$, K. Kodera ${ }^{4,5}$, J. E. Box ${ }^{6,7}$, T. Nakaegawa ${ }^{4}$, and K. Kawamura ${ }^{1}$ \\ ${ }^{1}$ National Institute of Polar Research, 10-3 Midoricho, Tachikawa, Tokyo, 190-8518, Japan \\ ${ }^{2}$ Scripps Institution of Oceanography, University of California, San Diego, La Jolla, CA 92093, USA \\ ${ }^{3}$ NASA Goddard Institute for Space Studies, New York, NY 10025, USA \\ ${ }^{4}$ Meteorological Research Institute, Tsukuba, 305-0052, Japan \\ ${ }^{5}$ Solar Terrestrial Environment Laboratory, Nagoya University, Nagoya, Japan \\ ${ }^{6}$ Byrd Polar Research Center, The Ohio State University, Columbus, OH 43210, USA \\ ${ }^{7}$ Department of Geography, The Ohio State University, Columbus, OH 43210, USA
}

Correspondence to: T. Kobashi (kobashi.takuro@nipr.ac.jp)

Received: 28 September 2012 - Published in Clim. Past Discuss.: 8 November 2012

Revised: 15 February 2013 - Accepted: 25 February 2013 - Published: 8 March 2013

\begin{abstract}
The surface temperature of the Greenland ice sheet is among the most important climate variables for assessing how climate change may impact human societies due to its association with sea level rise. However, the causes of multidecadal-to-centennial temperature changes in Greenland temperatures are not well understood, largely owing to short observational records. To examine these, we calculated the Greenland temperature anomalies $\left(\mathrm{GTA}_{[\mathrm{G}-\mathrm{NH}]}\right)$ over the past $800 \mathrm{yr}$ by subtracting the standardized northern hemispheric $(\mathrm{NH})$ temperature from the standardized Greenland temperature. This decomposes the Greenland temperature variation into background climate $(\mathrm{NH})$; polar amplification; and regional variability $\left(\mathrm{GTA}_{[G-N H]}\right)$. The central Greenland polar amplification factor as expressed by the variance ratio Greenland/NH is 2.6 over the past $161 \mathrm{yr}$, and 3.3-4.2 over the past $800 \mathrm{yr}$. The GTA $[\mathrm{G}-\mathrm{NH}]$ explains $31-35 \%$ of the variation of Greenland temperature in the multidecadal-tocentennial time scale over the past $800 \mathrm{yr}$. We found that the $\mathrm{GTA}_{[\mathrm{G}-\mathrm{NH}]}$ has been influenced by solar-induced changes in atmospheric circulation patterns such as those produced by the North Atlantic Oscillation/Arctic Oscillation (NAO/AO). Climate modeling and proxy temperature records indicate that the anomaly is also likely linked to solar-paced changes in the Atlantic meridional overturning circulation (AMOC) and associated changes in northward oceanic heat transport.
\end{abstract}

\section{Introduction}

The surface air temperature over Greenland is known to be affected by drivers such as large volcanic eruptions, changes in solar output, or anthropogenic forcings and by variability patterns such as the North Atlantic Oscillation (NAO) and/or the Atlantic multidecadal oscillation (AMO) (Hurrell, 1995; Hanna and Cappelen, 2003; Vinther et al., 2003; Box et al., 2009). These regional variations have caused Greenland temperature to depart from the baseline trend defined by the average northern hemispheric $(\mathrm{NH})$ temperatures (Box et al., 2009). For more accurate projections of the future mass balance of the Greenland ice sheet and of sea level changes, it is critical to understand the mechanisms underlying Greenland surface temperature changes.

Greenland surface temperature, especially the temperature in western Greenland, fluctuates in a manner inverse to the observed NAO index (Hanna and Cappelen, 2003; Vinther et al., 2003; Box et al., 2009). The NAO, an important mode of climate variability in the North Atlantic that influences North Africa, Europe and North America, particularly in the winter, is often represented by the difference in sea level pressure between the Azores high and the Icelandic low (Hurrell, 1995). Recent studies have shown that NAO variability is closely linked to changes in the atmospheric blocking regime, which constitutes quasi-stationary anti-cyclonic systems interrupting the normal zonal flow (Barriopedro et 
al., 2008; Woollings et al., 2010; Häkkinen et al., 2011; Rimbu and Lohmann, 2011). When the NAO index is positive, west Greenland temperature in particular decreases due to stronger northerly winds, whereas northwestern Europe experiences warmer temperatures in response to stronger westerlies, and when the NAO index is negative, the opposite effects are observed (Wanner et al., 2001). An influence of the NAO on the average NH temperatures has also been suggested (Hurrell, 1996). Climate models (Shindell et al., 2001) and observations (Kodera, 2002; Ineson et al., 2011) indicate a link between NAO-like variability and changes in solar output (Gray et al., 2010).

During periods of stronger solar activity, ozone in the upper stratosphere and lower mesosphere absorbs the increased ultraviolet irradiance, which increases the ambient temperature. Higher ultraviolet irradiance also increases ozone production through the photodissociation of molecular oxygen in the stratosphere (Haigh, 1999), and the enhanced ozone in turn absorbs more radiation and further increases temperature. Temperature changes maximize in the tropical latitudes, so that the temperature gradients between low and high latitudes in the stratosphere are amplified, creating stronger tropospheric westerly winds with associated pressure and temperature fields extending down to the surface where they resemble positive NAO-like atmospheric patterns (Shindell et al., 2001; Kodera and Kuroda, 2002). During periods of lower solar activity such as the Maunder Minimum, climate models and proxy records both suggest negative NAO-like patterns and warm southwest (especially southern edge of) Greenland temperature anomalies (Shindell et al., 2001). The proxy-derived spatial pattern of temperature change from the Medieval Warm Period to the Little Ice Age was shown to possess some features resembling the NAO/AO (Arctic Oscillation) pattern (Mann et al., 2009).

In this study, we investigated the variations in the Greenland temperature anomaly using a recently developed Greenland temperature record (Kobashi et al., 2010, 2011) derived from trapped air in the GISP2 Greenland ice core from the Greenland Summit station and using two proxy average NH temperature reconstructions (Moberg et al., 2005; Mann et al., 2009). Proposed mechanisms for the temperature variations were then investigated with a climate model (GISS-ER) and grid proxy reconstruction of global temperatures (Mann et al., 2009). We note that the inferences investigated in this paper were further tested and developed in a companion paper (Kobashi et al., 2012) dealing with the past $4000 \mathrm{yr}$ of Greenland temperature record (Kobashi et al., 2011).

\section{Correlation coefficients and significance}

In this study, the Pearson product-moment correlation coefficient was calculated to evaluate the strength of a correlation. To take into account the autocorrelation of time series, the number of effective degrees of freedom $\left(\mathrm{df}_{\mathrm{e}}\right)$ for $p$ statistics was estimated from the effective sample size $\left(N_{\mathrm{e}}\right)$, which depends on the effective decorrelation time $\left(T_{\mathrm{e}}\right)$ after Ito and Minobe (2010). The two relevant time series were represented by $X$ and $Y$, and the sample size is $N$. Here, the time interval $(\Delta t)$ was $1 \mathrm{yr}$. Therefore, $N_{\mathrm{e}}=N \Delta t / T_{\mathrm{e}}$ and $\mathrm{df}_{\mathrm{e}}=N_{\mathrm{e}}-2$. For the correlation coefficients, $T_{\mathrm{e}}$ was estimated as $T_{\mathrm{e}}=\Delta t \sum_{\tau=-N}^{N}\left(\rho_{X X}(\tau) \rho_{Y Y}(\tau)+\rho_{X Y}(\tau) \rho_{Y X}(\tau)\right)$, where $\tau$ is a lag or a lead in years, and $\rho$ is the correlation coefficient of the two time series indicted by the subscripts ( $X X$ and $Y Y$ are autocorrelations). The range of $\Sigma(-N, N)$ was defined by increasing lead or lag $(\tau)$ until $\rho$ became zero. Then, $p$ values of the correlation coefficients were calculated from a two-sided Student's $t$ distribution with the effective sample size $(\mathrm{Ne})$ described above. We consider a $>90 \%$ confidence level $(p=0.1)$ as a significant correlation, but we reported all $p$ values when $p$ value is less than 0.1 allowing the assessments of degree of significance. Shared variance (\%) of two time series was calculated as the square of the correlation coefficient of the two time series.

\section{Observational period (1850-2010)}

\subsection{Greenland temperature anomaly}

We first investigated a reconstruction of Greenland nearsurface air temperature in the vicinity of the Summit station $\left(72^{\circ} 35^{\prime} \mathrm{N}, 38^{\circ} 27^{\prime} \mathrm{W}\right)$ during the $1850-2010$ period generated from observed temperature records and regional climate model output (Box et al., 2009). Uncertainties of the temperature record in earlier periods are likely larger as observational constrains are limited (Box et al., 2009). We compared the record with the average temperatures of the $\mathrm{NH}$ (Brohan et al., 2006) (HadCRUT3, Fig. 1). We noted that the Summit air temperature is highly correlated $(r=0.92, p<0.01$; Fig. 2) with the average surface air temperature of the entire Greenland ice sheet (Box et al., 2009; Kobashi et al., 2011), indicating that the Summit temperatures reconstructed from ice cores are a reliable proxy for the surface temperatures of the entire ice sheet. Hereinafter, we call the Summit temperature time series "Greenland temperature". Furthermore, the reconstructed Summit temperature for the 1855-2010 period is significantly correlated $(r=0.77, p<0.01)$ with the long record of observed temperatures from the Ilulissat settlement (Cappelen, 2011) located on the west coast of Greenland.

The Greenland and $\mathrm{NH}$ average temperatures over the past $161 \mathrm{yr}$ follow similar characteristics $(r=0.66, p=0.17$; after linear de-trending $r=0.47, p=0.09$ ) but with noticeable differences (Box et al., 2009) as the top panel of Fig. 1 illustrates. Differences in the temperature trends for Greenland and the $\mathrm{NH}$ at the decadal scale include stronger Greenland warming during the decade 1920-1930, decades-long cooling during the 1930s-1980s, and another warming episode in the 1990s and 2000s, all with similar magnitudes (Fig. 1). 


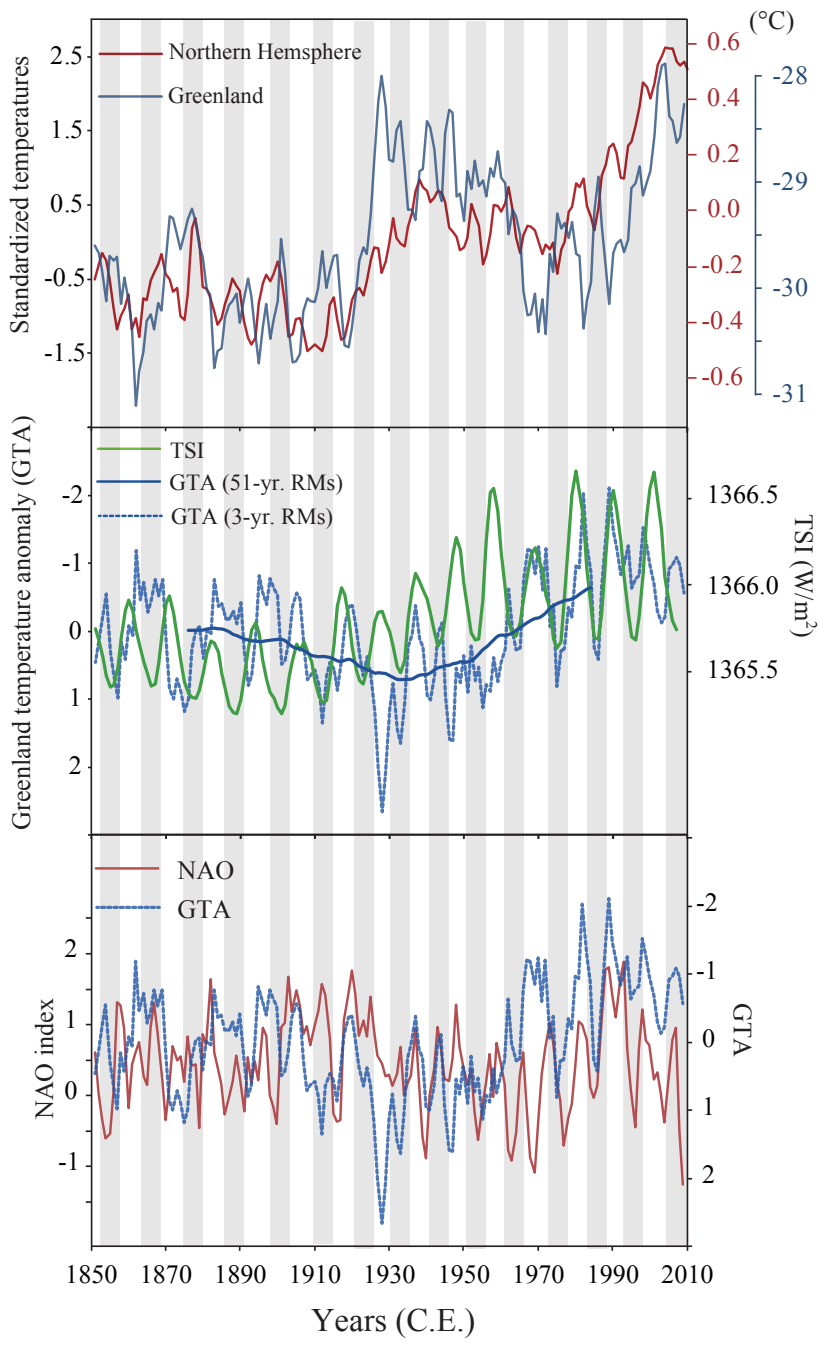

Fig. 1. Climate records for the 1850-2010 period. Top panel: annual average Greenland Summit temperature (Box et al., 2009) and annual average NH temperature (HadCRUT3) (Brohan et al., 2006). Twenty-year root mean squared errors (RMSE) for the Summit temperature are estimated to be less than $1.6^{\circ} \mathrm{C}$ (Box et al., 2009). Middle panel: Greenland temperature anomaly $\left(\mathrm{GTA}_{[\mathrm{G}-\mathrm{NH}]}\right)$ vs. TSI with background (Wang et al., 2005). Bottom panel: GTA $[\mathrm{G}-\mathrm{NH}]$ vs. winter NAO (DJFM; CRU) (Jones et al., 1997; Osborn, 2011). All time series are smoothed by 3-yr RMs except the Greenland temperature in 51-yr RMs. Shaded areas are periods of low solar activity. Note that the axis for GTA is reversed.

As a result, the decadal average temperatures in Greenland in the 1930s and 2000s are of similar magnitude (Fig. 1) as also found in changes in glacial extents in Greenland (Bjørk et al., 2012). Unlike in Greenland, the NH temperature during the last decade (2001-2010) was the warmest for the observed period (Fig. 1). To quantitatively investigate why Greenland temperature deviates from the $\mathrm{NH}$ temperature trend, we calculated the Greenland temperature anomaly $\left(\mathrm{GTA}_{[\mathrm{G}-\mathrm{NH}]}\right)$ by subtracting the standardized $\mathrm{NH}$ temperatures from the standardized Greenland temperatures (Fig. 1).

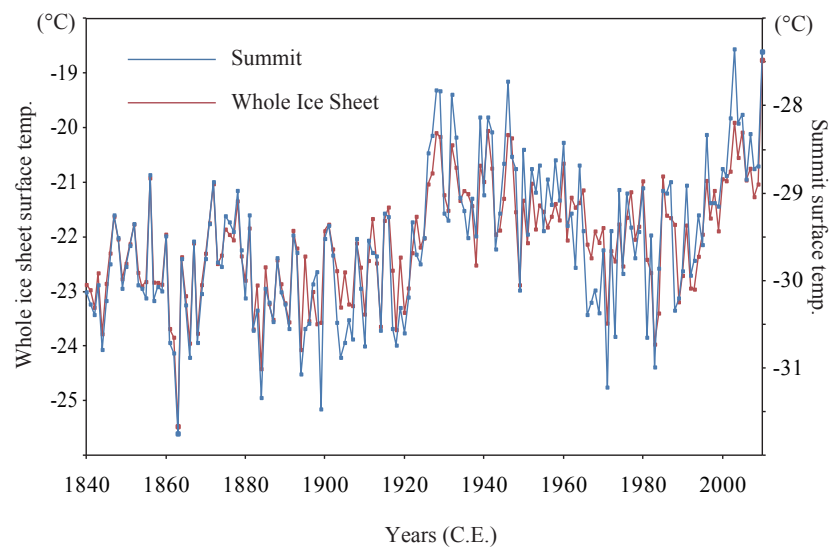

Fig. 2. The Greenland Summit surface air temperature and the whole Greenland ice sheet surface temperature were reconstructed for the last $170 \mathrm{yr}$ from a spatial-temporal data fusion between the output of a regional climate model (Polar MM5) (Box et al., 2009) and in situ observations (Kobashi et al., 2011).

$$
\begin{aligned}
\mathrm{GTA}_{[\mathrm{G}-\mathrm{NH}]} & =\text { standardized Greenland temperatures } \\
& - \text { standardized NH temperatures }
\end{aligned}
$$

This calculation allowed us to decompose Greenland temperature variation into three factors: background climate $(\mathrm{NH})$; polar amplification factor (the ratio of the standard deviations for Greenland and $\mathrm{NH}$ temperatures); and regional variability $\left(\mathrm{GTA}_{[\mathrm{G}-\mathrm{NH}]}\right)$, assuming that the polar amplification factor is constant over the concerned period. The central Greenland polar amplification factor for inter-annual to multidecadal variation is 2.6 over the past $161 \mathrm{yr}$.

In detail, we calculated the Greenland temperature anomaly $\left(\mathrm{GTA}_{[\mathrm{G}-\mathrm{NH}]}\right)$ from the $\mathrm{NH}$ trend for a period of $161 \mathrm{yr}$ as follows. The variance of the inter-annual variability of the standardized Greenland temperature is higher than that of the standardized $\mathrm{NH}$ temperature over the past $161 \mathrm{yr}$, potentially affecting the longer-term variation of the $\mathrm{GTA}_{[\mathrm{G}-\mathrm{NH}]}$. Therefore, a 3-yr running mean (RM) filter is applied to the raw data for Greenland temperature and the $\mathrm{NH}$ temperature to reduce the inter-annual variability, so the $\mathrm{GTA}_{[\mathrm{G}-\mathrm{NH}]}$ reflects the decadal to multidecadal temperature anomalies in Greenland temperature with respect to the $\mathrm{NH}$ temperature trend. After the filtering, the NH and Greenland temperature time series are standardized to calculate the $\mathrm{GTA}_{[\mathrm{G}-\mathrm{NH}]}$. For the standardization, we subtracted the average value from each time series and divided the time series by the standard deviation of the time series; the resulting time series had means of zero and standard deviations of one.

\subsection{Links between NAO/AO, GTA, and solar variability during the observational period}

Near-surface air temperatures in much of Greenland's area exhibit a negative correlation with the NAO index especially 
in winter (Box, 2002). As annual temperature variability is dominated by winter temperature variability in Greenland (Vinther et al., 2010), we hypothesize that the variation in the $\mathrm{GTA}_{[\mathrm{G}-\mathrm{NH}]}$ is linked to the NAO/AO. Indeed, the $\mathrm{GTA}_{[\mathrm{G}-\mathrm{NH}]}$ is significantly negatively correlated with the averages of the winter (DJFM) NAO index (Jones et al., 1997; Osborn, 2011) with a correlation coefficient of $r=-0.44$ ( $p=0.06$ ) for the 1960-2007 with 3-yr RMs over the past $48 \mathrm{yr}$ as in Fig. 1. Cooling signals associated with large volcanic eruptions are known to be similar to cooling signals of weaker solar activity, which makes it difficult to differentiate solar and volcanic signals (Lean and Rind, 2008; Gray et al., 2010). However, solar signals are out-of-phase between the $\mathrm{NH}$ and Greenland temperatures (cooling in NH and warming in Greenland, and vice versa), but volcanic signals are in-phase between the $\mathrm{NH}$ and Greenland temperatures (cooling in $\mathrm{NH}$ and Greenland), providing a rare opportunity to differentiate the two natural climate forcings.

The inter-annual variations of the $\mathrm{GTA}_{[\mathrm{G}-\mathrm{NH}]}$ correlates weakly but significantly with the 11-yr solar cycle for the 1960-2007 period $(r=-0.29, p=0.09)$, as shown in the bottom panel of Fig. 1, although the correlation is not significant $(r=-0.27, p=0.35)$ for the entire observational period (1851-2007). The inconsistency may relate to the empirical findings that climate is more sensitive to the solar forcing at the multidecadal-to-century time scale than shorter variations of solar activity such as the 11-yr solar cycle (Waple et al., 2002; Gray et al., 2010). In the multidecadal-to-centennial time scale, the $\mathrm{GTA}_{[\mathrm{G}-\mathrm{NH}]}$ indicates an increasing trend until the 1930s. Note the GTA ${ }_{[\mathrm{G}-\mathrm{NH}]}$ vertical axis is reversed in Fig. 1. The GTA ${ }_{[\mathrm{G}-\mathrm{NH}]}$ thereafter showed a decreasing trend, indicating that Greenland temperature decreased relative to that of the $\mathrm{NH}$ until $\sim 1990$. Then, the $\mathrm{GTA}_{[\mathrm{G}-\mathrm{NH}]}$ increased to the present associated with more rapid warming in Greenland than that in the NH (Fig. 1). The multidecadal trend of the $\mathrm{GTA}_{[\mathrm{G}-\mathrm{NH}]}$ is similar to the long-term variation of solar activity over the past $160 \mathrm{yr}$ (Fig. 1). However, the observational records are too short to support a causal relationship between the solar variability and the $\mathrm{GTA}_{[\mathrm{G}-\mathrm{NH}]}$ in the multidecadal-to-centennial time scale.

\section{The past $800 \mathrm{yr}$ of Greenland temperature anomaly $\left(\mathbf{G T A}_{[\mathrm{G}-\mathrm{NH}]}\right)$}

To evaluate the robustness of the apparent solar influence on the multidecadal-to-centennial GTA $[\mathrm{G}-\mathrm{NH}]$ variation, we examined records from the past $800 \mathrm{yr}$ (Fig. 3). For the $\mathrm{NH}$ temperature, two proxy-based reconstructions by Moberg et al. (2005) and Mann et al. (2009) were used as in Fig. 3. For Greenland temperature, we used a recently developed record of the temperature at Summit that was reconstructed from air trapped in the GISP2 ice core (Kobashi et al., 2010). The new temperature record addresses deficiencies in the existing Greenland temperature proxies, such as $\delta^{18} \mathrm{O}_{\text {ice }}$ and borehole thermometry (Kobashi et al., 2011), providing decadal averages owing to gas diffusion in the firn (unconsolidated snow) layer. Thus, this new temperature record is not affected by large seasonal temperature swings (Kobashi et al., 2010). Owing to gas and heat diffusion in the firn layer (porous unconsolidated snow), the temperature record represents decadal averages (Kobashi et al., 2010). For the assessments of solar influence on $\delta^{18} \mathrm{O}_{\text {ice }}$, we refer to Kobashi et al. (2012).

The NH and Greenland temperatures exhibit similar trends, with the characteristics of the Medieval Warm Period in 1200-1450, the Little Ice Age in 1450-1850, and recent warming (Fig. 3). We then derived two $800-\mathrm{yr}$ GTAs $_{[\mathrm{G}-\mathrm{NH}]}$ by the same method used for the observational records, but fully taking into account uncertainties in temperature reconstructions (Fig. 3). For the data over the past $800 \mathrm{yr}$, we initially applied $21 \mathrm{RMs}$ to the $\mathrm{NH}$ and Greenland temperatures prior to standardization to illustrate multidecadal to centennial variability in the $\mathrm{GTA}_{[\mathrm{G}-\mathrm{NH}]}$. We standardized the time series by subtracting the means and dividing the time series by the standard deviations, so the resulting time series have means of zero and standard deviations of 1 . Ninety-five percent confidence intervals for the NH (Mann et al., 2009) and Greenland (Kobashi et al., 2010) temperatures with $21 \mathrm{RMs}$ were estimated by Monte Carlo simulation as follows. Gaussian white noise signals with a standard deviation of 1 and a mean of zero are generated and then multiplied by the reported $1 \sigma$ values for the NH (Mann et al., 2009) and Greenland (Kobashi et al., 2010) temperature data for each year. These modified signals were then added to the original $\mathrm{NH}$ and Greenland temperature time series. By repeating this calculation 1000 times, 1000 synthetic NH and Greenland temperature time series were generated. For each time series, $21 \mathrm{RMs}$ were applied. The $1 \sigma$ values of the $\mathrm{NH}$ and Greenland temperature time series with the 21 RMs were then estimated as standard deviations from the 1000 synthetic time series.

To address the uncertainty in the $\mathrm{NH}$ temperatures in the 21 RMs of Moberg et al. (2005), we directly used the uncertainty (uncertainty A) due to the variance among low-resolution proxies, but we did not include the uncertainty (uncertainty B) in the scaling factor or the constant adjustment term (uncertainty $\mathrm{C}$ ), because these uncertainties were not relevant for standardizing time series. The estimated $1 \sigma$ values of the $\mathrm{NH}$ and Greenland temperatures with $21 \mathrm{RMs}$ were scaled for the standardized $\mathrm{NH}$ and Greenland temperatures in 21 RMs using the same values for standardizing the $\mathrm{NH}$ and Greenland temperatures with 21 RMs. The uncertainties in the $\mathrm{GTA}_{[\mathrm{G}-\mathrm{NH}]}$ were derived from the equation for the propagation of error: $\sigma \mathrm{GTA}=\sqrt{(\sigma \mathrm{stn} . \mathrm{NH})^{2}+(\sigma \text { stn. Greenland })^{2}}$, where $\sigma \mathrm{GTA}_{[\mathrm{G}-\mathrm{NH}]}, \sigma$ stn. $\mathrm{NH}$, and $\sigma$ stn. Greenland are the standard deviations of the $\mathrm{GTA}_{[\mathrm{G}-\mathrm{NH}]}$, the standardized $\mathrm{NH}$ 


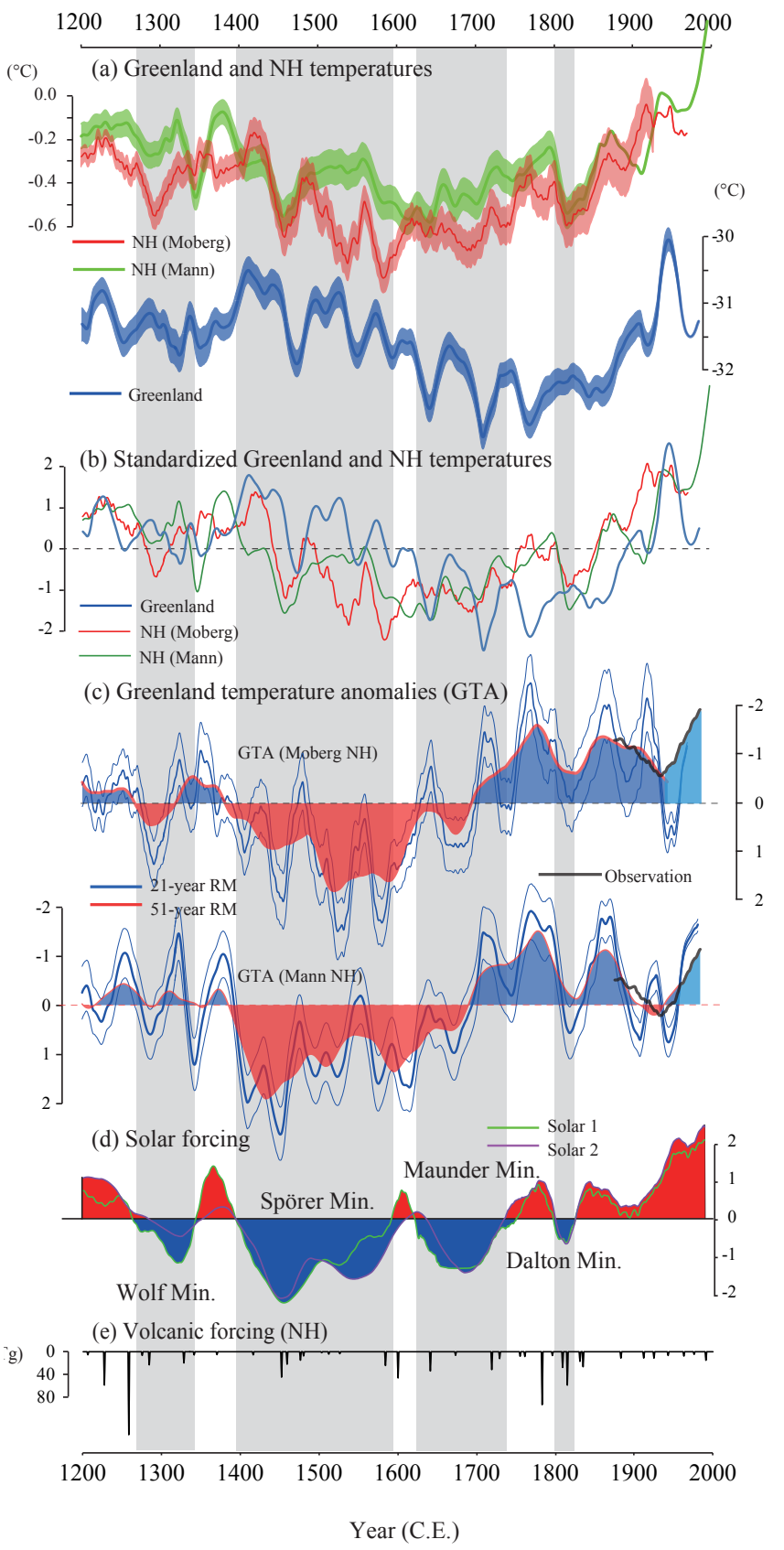

Fig. 3. Climate records for the 1200-2010 period. (a) Greenland temperature (blue) (Kobashi et al., 2010) and the NH temperature from Moberg et al. (2005) (red) and Mann et al. (2009) (green) in 21 RMs with $95 \%$ confidence intervals ( $2 \sigma$ ). (b) The blue line is the standardized Greenland temperature (Kobashi et al., 2010). The red and green lines are the standardized NH temperatures (Moberg et al., 2005; Mann et al., 2009). (c) Greenland temperature anomalies $\left(\mathrm{GTA}_{[\mathrm{G}-\mathrm{NH}]}\right)$ calculated from Greenland temperature and the NH temperature, as shown in panel (b). The blue and red lines are smoothed by $21 \mathrm{RMs}$ with $95 \%$ confidence intervals $(2 \sigma)$ and by 51 RMs, respectively. The area between the red line and zero is colored blue for the region above zero and red for the region below zero. The black line is the GTA $[\mathrm{G}-\mathrm{NH}]$ calculated from the observed temperatures $(51 \mathrm{RMs})$ in Fig. 1. Transparent light blue shading indicates areas below the observed GTA $[\mathrm{G}-\mathrm{NH}]$ (black line) and above zero. Values of -1.27 and -0.49 are added to the observed GTAs $[\mathrm{G}-\mathrm{NH}]$ with the NHs by Moberg et al. and Mann et al., respectively, to account for the differences in the average $\mathrm{GTAs}_{[\mathrm{G}-\mathrm{NH}]}$ between the proxy and the observations for the overlapping period. Note that the y-axis of the GTA $[\mathrm{G}-\mathrm{NH}]$ is reversed to allow for comparison with the solar variability. (d) The purple line represents the solar forcing from Bard et al. (2000) and Crowley (2000) spliced into that from Lean et al. (1995), and the green line is from Delaygue and Bard (2009) spliced into that from Wang et al. (2005) The areas are colored red when the values are above zero (stronger sun) and blue when the values are below zero (weaker sun). The standardized time series of the solar forcings is shown. The grey areas are the periods of weaker suns used for the statistical tests. (e) The volcanic forcing for the NH from Gao et al. (2008) is plotted as a reference. 
temperature, and the standardized Greenland temperature, respectively.

The two GTAs $[\mathrm{G}-\mathrm{NH}]$ exhibit similar characteristics over the past $800 \mathrm{yr}(r=0.79, p=0.02)$, partly because two $\mathrm{NH}$ temperature records closely resemble each other, indicating that the temperature signal is a robust feature of the GTA $_{[\mathrm{G}-\mathrm{NH}]}$. The GTAs ${ }_{[\mathrm{G}-\mathrm{NH}]}$ explains $31-35 \%$ of the variation of Greenland temperature over the past $800 \mathrm{yr}$ in the multidecadal to centennial time scale. The central Greenland polar amplification factor (=Greenland/NH) over the past $800 \mathrm{yr}$ ranges from 3.3 for the $\mathrm{NH}$ temperature from Moberg et al. (2005) to 4.2 for the $\mathrm{NH}$ temperature from Mann et al. (2009). The GTAs $s_{[\mathrm{G}-\mathrm{NH}]}$ show more negative values (with Greenland being cooler than the $\mathrm{NH}$ ) before 1400 and after 1700 and positive values (with Greenland being warmer than the $\mathrm{NH}$ ) between 1400 and after 1700, indicating that there was a more positive NAO-like pattern before 1400 and after 1700 , and a more negative pattern in the intervening period. The persistent positive NAO during the Medieval Warm Period is consistent with the results of a recent study (Trouet et al., 2009).

\section{Solar influence on Greenland temperature anomalies (GTA $[$ G-NH]}

To investigate the relationship between the $\mathrm{GTA}_{[\mathrm{G}-\mathrm{NH}]}$ and changes in solar activity over the past $800 \mathrm{yr}$, we used two solar forcing reconstructions based on ${ }^{10} \mathrm{Be}$ in ice cores from Antarctica (Bard et al., 1997; Crowley, 2000). Cross wavelet analyses (Grinsted et al., 2004) in Fig. 4 revealed that Greenland temperature has a weak anti-phase correlation with the total solar irradiance (TSI) around the period of $\sim 128 \mathrm{yr}$. In contrast, the NH temperature generally exhibits a weak inphase relationship with the TSI over the past $800 \mathrm{yr}$ (Fig. 4). As a result, solar signals are enhanced in the $\mathrm{GTA}_{[\mathrm{G}-\mathrm{NH}]}$ and exhibit significant anti-phase with the TSI, especially around the period of $\sim 128 \mathrm{yr}$ (Fig. 4 ).

To test the null hypothesis that solar variation did not cause changes in GTAs $[\mathrm{G}-\mathrm{NH}]$ over the past $800 \mathrm{yr}$, we conducted a statistical test "re-sampling" (Ito and Minobe, 2010). We determined the periods of stronger and weaker solar output using two times series of solar forcing, as shown in Fig. 3. The two time series of solar forcing were smoothed by $21 \mathrm{RMs}$, and then standardized. The two resulting time series were averaged to generate a representative time series of solar forcing. We simply defined the periods of stronger solar output as periods when the standardized solar forcing was positive, and the periods of weaker solar output were defined as the periods when the standardized solar forcing was negative (Table 1). In total, there were $384 \mathrm{yr}$ of stronger solar output, and $417 \mathrm{yr}$ of weaker solar output.

Then, the averages of the $\mathrm{GTA}_{[\mathrm{G}-\mathrm{NH}]}$ corresponding to the periods of "stronger" and "weaker" solar output were calculated. The averages of the $\mathrm{GTA}_{[\mathrm{G}-\mathrm{NH}]}$ for stronger and
Table 1. The periods of stronger and weaker solar output over the past $800 \mathrm{yr}$.

\begin{tabular}{clccc}
\hline$\#$ & $\begin{array}{l}\text { Solar } \\
\text { output }\end{array}$ & Top & Bottom & Duration \\
\hline 1 & Strong & 2000 & 1826 & 175 \\
2 & Weak & 1825 & 1800 & 26 \\
3 & Strong & 1799 & 1740 & 60 \\
4 & Weak & 1739 & 1625 & 115 \\
5 & Strong & 1624 & 1597 & 28 \\
6 & Weak & 1596 & 1396 & 201 \\
7 & Strong & 1395 & 1345 & 51 \\
8 & Weak & 1344 & 1270 & 75 \\
9 & Strong & 1269 & 1200 & 70 \\
\hline
\end{tabular}

weaker solar output were subtracted to obtain the average difference in the $\mathrm{GTA}_{[\mathrm{G}-\mathrm{NH}]}$ between the periods of stronger and weaker output. Second, the order of the 11 durations in Table 1 was randomly shuffled. Based on the new order of the durations, 11 periods were calculated from 2000 to $1200 \mathrm{CE}$. Periods of stronger and weaker solar output were defined as the odd and even numbers, respectively, in the new order. In addition, the assignments of odd and even numbers to periods of stronger and weaker solar output were randomly replaced. A synthetic GTA $[\mathrm{G}-\mathrm{NH}]$ is generated by adding Gaussian white noise (with a zero mean and a standard deviation of 1$)$ multiplied by the uncertainties $(1 \sigma)$ of the previously calculated GTAs $s_{[\mathrm{G}-\mathrm{NH}]}$. The averages of the GTAs ${ }_{[\mathrm{G}-\mathrm{NH}]}$ from the periods of stronger and weaker solar output were then calculated, and the difference between these two averages was calculated. This process was repeated 10000 times (1000 times for maps) to generate a set of 10000 samples (1000 samples for maps) for the differences. Percentile ranks were calculated and used to test the null hypothesis with onesided tests as we are only interested in Greenland cooling (warming) not warming (cooling) during stronger (weaker) sun, respectively, to determine the significance levels of the observed differences in the $\mathrm{GTA}_{[\mathrm{G}-\mathrm{NH}]}$ between periods of stronger and weaker solar output. We found that, for the $\mathrm{GTA}_{[\mathrm{G}-\mathrm{NH}]}$ with respect to the NH temperature of Moberg et al. (2005), the null hypothesis was rejected at the $99.9 \%$ significance level; for the $\mathrm{GTA}_{[\mathrm{G}-\mathrm{NH}]}$ with the NH temperature of Mann et al. (2009), the null hypothesis was rejected at the $98 \%$ confidence level. Therefore, we conclude that solar variability has caused changes in the $\mathrm{GTA}_{[\mathrm{G}-\mathrm{NH}]}$ over the past $800 \mathrm{yr}$.

One caveat for the calculation of the $\mathrm{GTA}_{[\mathrm{G}-\mathrm{NH}]}$ from Greenland temperature and the $\mathrm{NH}$ temperature is that the correlation of the $\mathrm{GTA}_{[\mathrm{G}-\mathrm{NH}]}$ with solar activity may arise entirely from the correlation between the $\mathrm{NH}$ temperatures and solar activity. To test the null hypothesis that the correlations between the $\mathrm{GTA}_{[\mathrm{G}-\mathrm{NH}]}$ and solar variability originate completely from the positive correlation between the $\mathrm{NH}$ temperature and solar variation, we conducted a statistical 

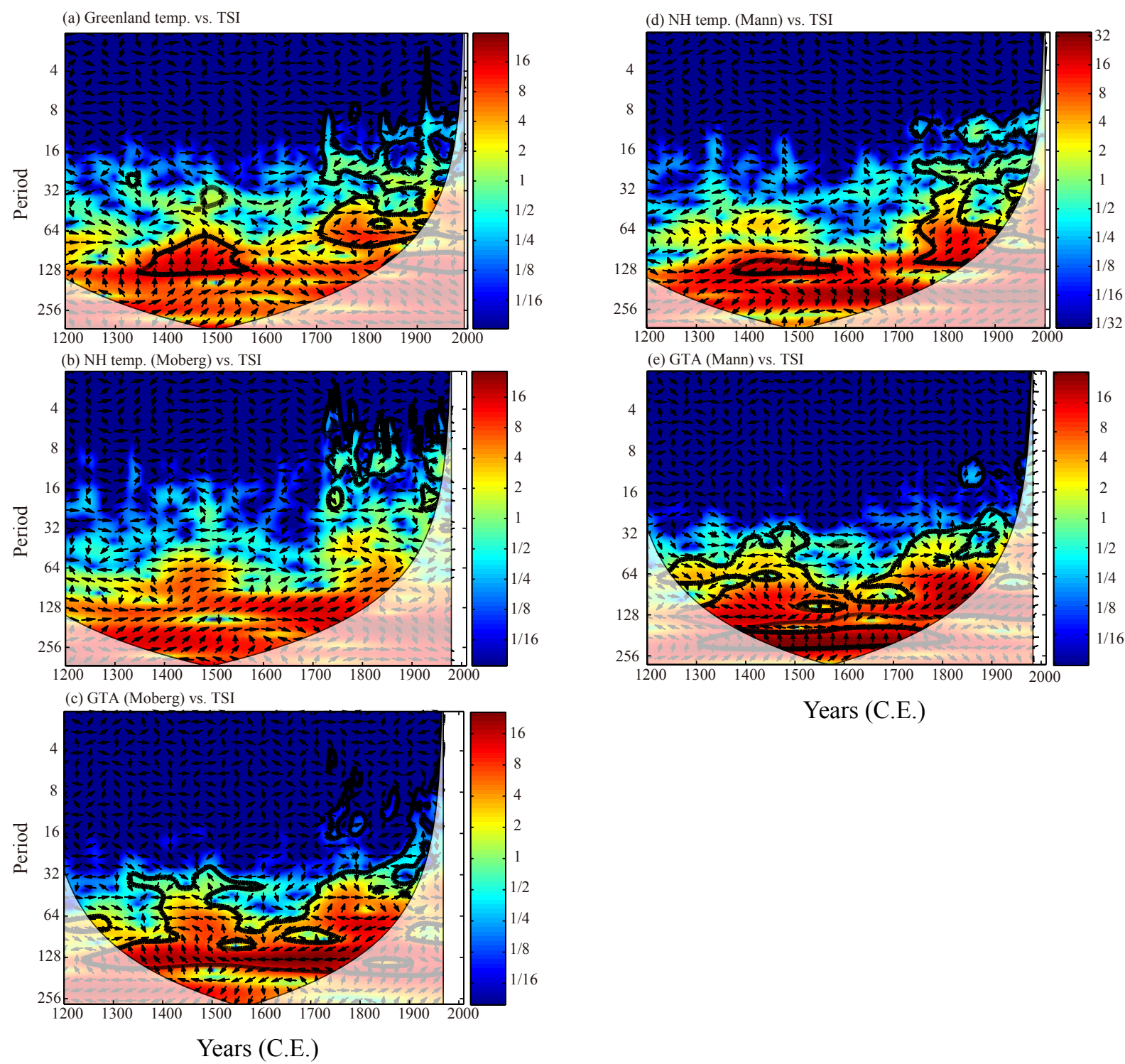

Fig. 4. Cross-wavelet transform (XWT) (Grinsted et al., 2004) of Greenland temperature, the NH temperature, the GTA $[\mathrm{G}-\mathrm{NH}]$, and the NAO, all vs. TSI, for 1200-2010. (a) Greenland temperature (Kobashi et al., 2010) vs. TSI (Lean et al., 1995; Bard et al., 2000; Crowley, 2000) for 1200-2010; (b) the NH temperature (Moberg et al., 2005) vs. TSI (Lean et al., 1995; Bard et al., 2000; Crowley, 2000) for 12002010; and (c) the GTA $[\mathrm{G}-\mathrm{NH}]$ with the NH temperature from Moberg et al. (2005) vs. TSI (Lean et al., 1995; Bard et al., 2000; Crowley, 2000) for 1200-2010; (d) the NH temperature (Mann et al., 2009) vs. TSI (Lean et al., 1995; Bard et al., 2000; Crowley, 2000); (e) the $\mathrm{GTA}_{[\mathrm{G}-\mathrm{NH}]}$ (Moberg et al., 2005) vs. TSI (Lean et al., 1995; Bard et al., 2000; Crowley, 2000). Annual resolution data are used for the analyses except the GTAs $s_{[\mathrm{G}-\mathrm{NH}]}$. The area between the grey lines represents the $95 \%$ confidence level relative to the noise (red). Arrows indicate relative phase relationships, with in-phase relationships denoted by right-facing arrows; arrows pointing straight down indicate that the phase of the TSI leads that of Greenland temperature, the NH temperature, or the $\mathrm{GTA}_{[\mathrm{G}-\mathrm{NH}]}$ by $90^{\circ}$. Shaded areas represent the cone of influence where edge effects may distort the results.

test by decomposing the standardized Greenland temperature $\left(\hat{T}_{\mathrm{G}}\right)$ and the standardized $\mathrm{NH}$ temperature $\left(\hat{T}_{\mathrm{NH}}\right)$ as follows:

$$
\begin{aligned}
& T_{\mathrm{a}}=\left(\hat{T}_{\mathrm{G}}+\hat{T}_{\mathrm{NH}}\right) / \sqrt{2} \\
& T_{\mathrm{b}}=\left(\hat{T}_{\mathrm{G}}-\hat{T}_{\mathrm{NH}}\right) / \sqrt{2} .
\end{aligned}
$$

We note that $T_{\mathrm{b}} \cong \mathrm{GTA}_{[\mathrm{G}-\mathrm{NH}]}$. Therefore, we can write it as the following:

$$
\begin{aligned}
& \hat{T}_{\mathrm{G}}=\left(T_{\mathrm{a}}+T_{\mathrm{b}}\right) / \sqrt{2} \\
& \hat{T}_{\mathrm{NH}}=\left(T_{\mathrm{a}}-T_{\mathrm{b}}\right) / \sqrt{2} .
\end{aligned}
$$


Table 2. Degrees $(\theta)$ of the maximum negative correlation coefficients, $r_{\mathrm{S}}(\theta)$, in various settings. The $95 \%$ confidence intervals $(2 \sigma)$ are shown for the past $800 \mathrm{yr}$ with the $\hat{T}_{\mathrm{NH}}$ from Moberg et al. (2005) and Mann et al. (2009), including uncertainties in Greenland temperature and the NH temperature. For the past $800 \mathrm{yr}$, two sets of solar forcing were used: (a) the dataset from Bard (Bard et al., 2000) and Crowley (Crowley, 2000) spliced into that of Lean et al. (Lean et al., 1995), and (b) the dataset from Delaygue and Bard (Delaygue and Bard, 2009) spliced into that of Wang et al. (Wang et al., 2005), as shown in Fig. 3.

\begin{tabular}{ll}
\hline Datasets & Degrees $(\theta)$ of maximum negative correlation, $r_{\mathrm{s}}(\theta)$ \\
\hline Past 161 yr (observational) & $129^{\circ}$ \\
Past 1000 yr; by Moberg et al. (2005) & (a) $111.7 \pm 1.0^{\circ}$; (b) $111.7 \pm 1.1^{\circ}$ \\
Past 1000 yr; by Mann et al. (2009) & (a) $113.8 \pm 0.8^{\circ}$; (b) $113.9 \pm 0.9^{\circ}$ \\
Simulated past 1000 yr; GISS (ensemble) & $114^{\circ}$ \\
\hline
\end{tabular}

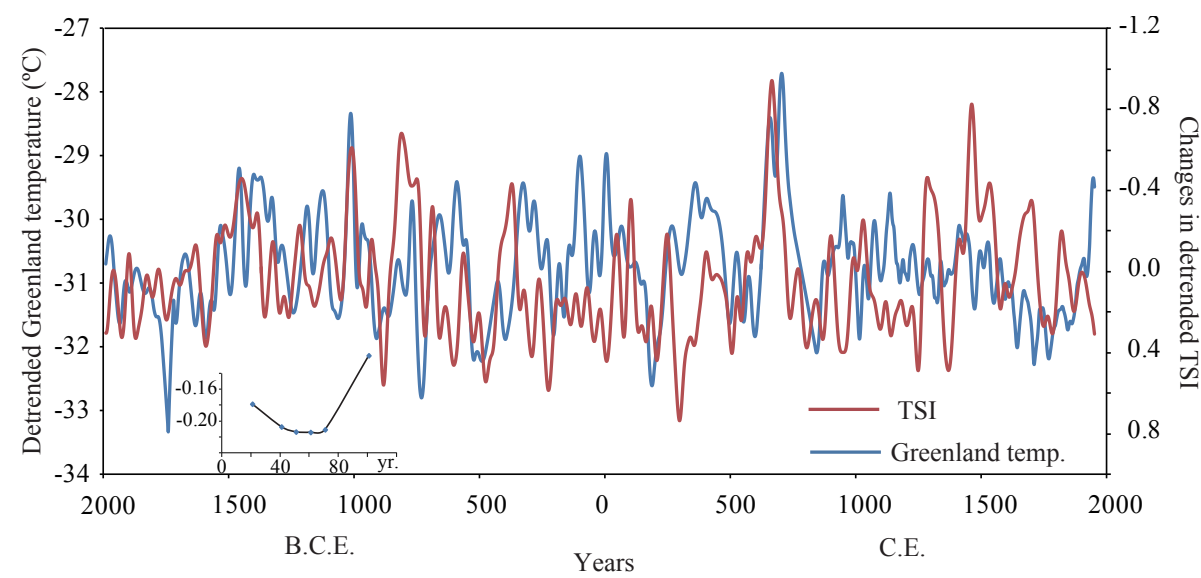

Fig. 5. Greenland temperature and solar activity over the past 4000 yr. Both time series are linearly de-trended and smoothed with $21-y r$ RMs. Greenland temperature (Kobashi et al., 2011) and solar activity (Steinhilber et al., 2009) have weak but significant negative correlation ( $r=-0.18 ; p=0.09$ ). 21-yr RMs were chosen as other smoothing with various periods showed lower confidence levels although they had in some cases higher correlation coefficients (see panel in left bottom). Note that the axis for the TSI is reversed.

Here, we define $T_{\mathrm{c}}(\theta)$ as

$T_{\mathrm{c}}(\theta)=T_{\mathrm{a}} \cos \theta+T_{\mathrm{b}} \sin \theta$

Clearly,

$T_{\mathrm{c}}(\theta)=\left\{\begin{array}{ll}T_{\mathrm{a}} ; & \theta=0^{\circ} \\ \hat{T}_{\mathrm{G}} ; & \theta=45^{\circ} \\ T_{\mathrm{b}} \cong \mathrm{GTA} ; & \theta=90^{\circ} \\ -\hat{T}_{\mathrm{NH}} ; & \theta=135^{\circ} \\ -T_{\mathrm{a}} ; & \theta=180^{\circ}\end{array}\right.$.

We then examined the correlation $\left(r_{\mathrm{s}}(\theta)\right)$ between changes in solar forcing and $T_{\mathrm{c}}(\theta)$ as $r_{\mathrm{s}}(\theta)=\left\langle\right.$ solar forcing, $\left.T_{\mathrm{c}}(\theta)\right\rangle$ under variable $\theta$. If the negative correlation between the $\mathrm{GTA}_{[\mathrm{G}-\mathrm{NH}]}$ and solar forcings originates completely from the positive correlation between $\hat{T}_{\mathrm{NH}}$ and solar forcing, the maximum negative correlation of $T_{\mathrm{c}}(\theta)$ should occur at $\theta \geq 135^{\circ}$. In contrast, if $\hat{T}_{\mathrm{G}}$ contains anti-phase components with solar forcing and thus contributes to the negative correlation between the $\mathrm{GTA}_{[\mathrm{G}-\mathrm{NH}]}$ and solar forcing, the maximum negative correlation of $r_{\mathrm{S}}(\theta)$ should occur in the range $45^{\circ}<\theta<135^{\circ}$. For the past $800 \mathrm{yr}$, the maximum negative correlation occurs around $110-114^{\circ}$ (Table 2). The results of the GISS simulations yielded a value similar to the observed value (Table 2). Therefore, we concluded that when solar activity is stronger (weaker), GTA $[\mathrm{G}-\mathrm{NH}]$ becomes lower (higher) due to higher (lower) $\mathrm{NH}$ temperatures and lower (higher) Greenland temperatures, respectively with the $99.0 \%$ significance level. The finding is also consistent with the fact that the Greenland temperature has a weak but significant negative correlation with solar activity over the past $4000 \mathrm{yr}$ as shown in Fig. 5 and Kobashi et al. (2012).

\section{Relationship between NH and Greenland temperatures with solar variability}

To further investigate the relationship between $\mathrm{NH}$ and Greenland temperature, we calculated another principal component of the two time series, "GTP $[\mathrm{G}-\mathrm{NH}]$ " (Greenland temperature plus $=$ standardized Greenland temperature + standardized NH temperature). In contrast to the GTA that illustrates out-of-phase climate signal (solar) of the two time series, $\mathrm{GTP}_{[\mathrm{G}-\mathrm{NH}]}$ can be used to investigate inphase climate signals in the two time series. Therefore, the 


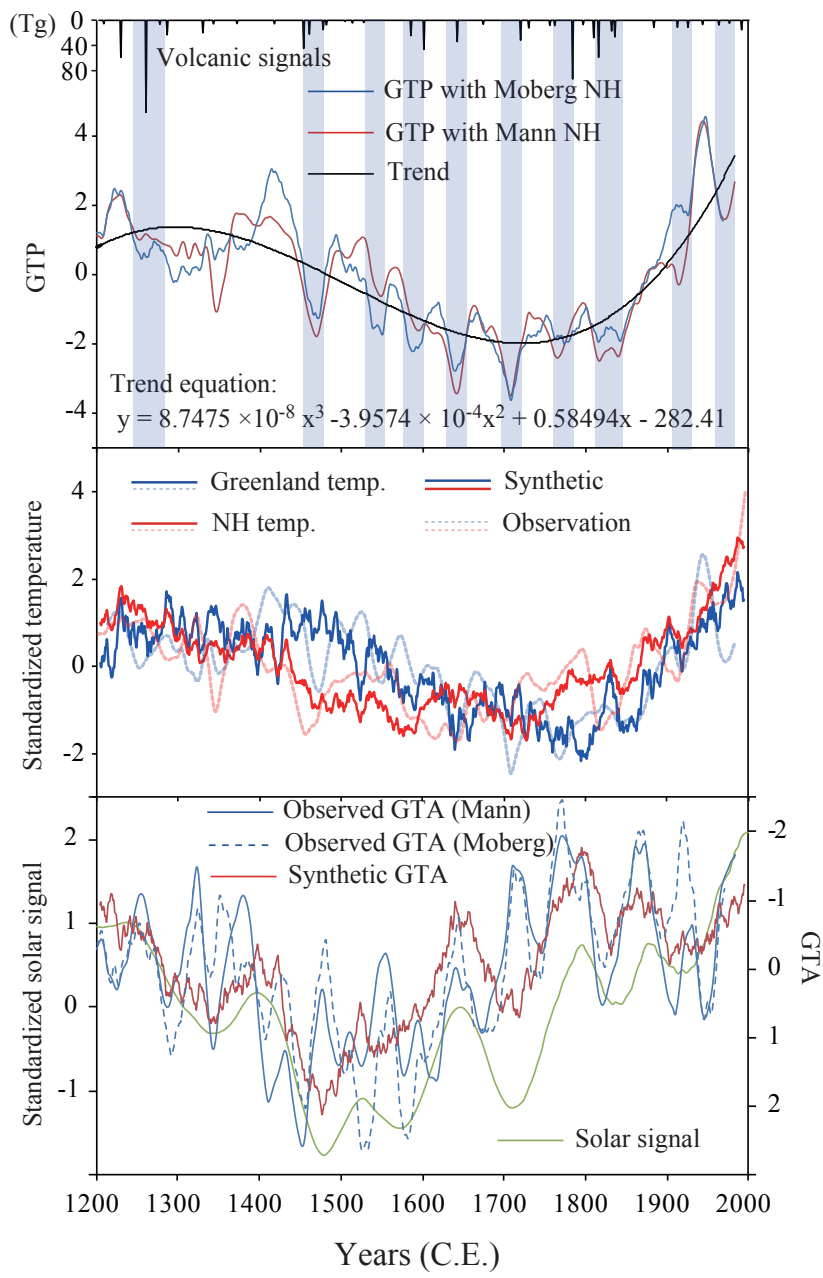

Fig. 6. Results of a simple numerical modeling. Top panel: $\mathrm{GTP}_{[\mathrm{G}+\mathrm{NH}]}$ and millennial trend from polynomial regression of $\mathrm{GTP}_{[\mathrm{G}+\mathrm{NH}]}$ with the NH temperature by Mann et al. (2009). The volcanic forcing for the $\mathrm{NH}$ from Gao et al. (2008) is plotted as a reference. Shaded areas are low GTP periods in the multidecadalto-centennial time scale. Note that many shaded areas coincide with large volcanic eruptions. Middle panel: synthetic and observed Greenland temperature (Kobashi et al., 2010) and NH temperature (Mann et al., 2009). Bottom panel: synthetic $\mathrm{GTA}_{[\mathrm{G}-\mathrm{NH}]}$, observed $\mathrm{GTAs}_{[\mathrm{G}-\mathrm{NH}]}$ with the NH temperatures by Mann et al. (2009) and Moberg et al. (2005), and standardized solar forcing (solar 2 in Fig. 3).

$\mathrm{GTP}_{[\mathrm{G}-\mathrm{NH}]}$ variation (Fig. 6, top panel) in the multidecadalto-centennial time scale likely reflects changes in volcanic forcing, increasing greenhouse gas forcing, and possibly internal variation of climate. Millennial-scale variation (Fig. 6, top panel) of the GTP $[\mathrm{G}-\mathrm{NH}]$ peaking in the $1300 \mathrm{~s}$ and $1700 \mathrm{~s}$ may reflect non-linear climate responses (e.g., growth of glaciers and ice sheets) to solar and/or volcanic forcing.

To illustrate the relationship between the $\mathrm{GTA}_{[\mathrm{G}-\mathrm{NH}]}$, $\mathrm{GTP}_{[\mathrm{G}+\mathrm{NH}]}$, and solar activity, we conducted a simple numerical experiment. To start with a synthetic hemispheric temperature without solar signals, a trend equation was derived from polynomial regression of the $\mathrm{GTP}_{[\mathrm{G}+\mathrm{NH}]}$ by the $\mathrm{NH}$ temperatures by Mann et al. (2009) and the Greenland temperature (Kobashi et al., 2010) (Fig. 6). These values of trend for a period of 1200-2000 were multiplied by 1.3. Then, the random numbers that were greater than or equal to 0 and less than 1 were generated, and multiplied by 8 . Then, these random numbers were added to the trend to produce seed time series. Synthetic NH temperature was produced by adding the seed to the standardized solar signal (solar 2 in Fig. 3) multiplied by two. Then, the synthetic NH temperature was smoothed by 11-yr RMs, and standardized. Synthetic Greenland temperature was generated by adding negative solar signals (multiplied by 3 ) to the synthetic $\mathrm{NH}$ temperatures. We note that all the coefficients were obtained to match the observed temperature records.

Then, the synthetic Greenland temperature was smoothed by 11-yr RMs, and standardized. Synthetic $\mathrm{GTA}_{[\mathrm{G}-\mathrm{NH}]}$ was calculated by subtracting the standardized synthetic NH temperature from the standardized synthetic Greenland temperature. In addition, synthetic $\mathrm{GTP}_{[\mathrm{G}+\mathrm{NH}]}$ was calculated by adding the standardized synthetic $\mathrm{NH}$ temperature and the standardized synthetic Greenland temperature. The fact that residuals between the model results and the observations ( $2 \sigma$ values are 1.6 for the standardized Greenland temperatures and 1.2 for the standardized NH temperatures as in Fig. 6, middle panel) are smaller than the long-term changes ( 3 for the standardized Greenland temperatures; 2.7 for the standardized NH temperatures as in Fig. 6, middle panel) supports the validity of the model.

We found that the synthetic GTA $[\mathrm{G}-\mathrm{NH}]$ captures the original solar signal $(r=-0.83)$ with slightly different features. The synthetic $\mathrm{GTA}_{[\mathrm{G}-\mathrm{NH}]}$ shows slightly higher correlation $(r=0.59)$ with the observed $\mathrm{GTA}_{[\mathrm{G}-\mathrm{NH}]}$ than the correlation $(r=-0.55)$ with the original solar signal (Fig. 6), indicating that the $\mathrm{GTA}_{[\mathrm{G}-\mathrm{NH}]}$ calculation introduces a minor alteration on solar signal as in Fig. 6. The synthetic $\mathrm{GTP}_{[\mathrm{G}+\mathrm{NH}]}$ can fully recover the original millennial trend $(r>0.99)$. In addition, the synthetic $\mathrm{GTA}_{[\mathrm{G}-\mathrm{NH}]}$ calculated with synthetic $\mathrm{NH}$ temperature without solar signal (the trend and noises only) and synthetic Greenland temperature (with negative solar signal) is more strongly correlated with the original solar signals, indicating that the observed correlation between the solar forcing and the $\mathrm{GTA}_{[\mathrm{G}-\mathrm{NH}]}$ is not an artifact of solar signal in the $\mathrm{NH}$ temperature.

\section{Climate model experiments}

We examined the climate model responses of the $\mathrm{GTAs}_{[\mathrm{G}-\mathrm{NH}]}$ in a coupled atmosphere-ocean climate model, the NASA Goddard Institute for Space Studies-ER (GISS-ER) simulation (Schmidt et al., 2006; Mann et al., 2009). The GISS model used in this study is the mode used in the CMIP3 simulations performed for the IPCC AR4 
(Schmidt et al., 2006). The model was run at $4 \times 5$ degrees of horizontal resolution with 23 vertical layers (many of the CMIP3 runs used a 20-layer version without gravity-wave drag but were otherwise identical). We performed a long control run to establish stable initial conditions, from which six transient runs were branched off, each extending from 850 to 1900 CE. Solar forcing was applied across the ultraviolet, visible and infrared spectra based on scaling by wavelength versus total irradiance using the relationships as observed in modern satellite data. The total irradiance over time was based on the time series of ${ }^{10} \mathrm{Be}$ data from a South Pole ice core (Bard et al., 2007) and by taking into account a small long-term geomagnetic modulation (Korte and Constable, 2005) and a polar enhancement factor. The amplitude was scaled to provide a top-of-the-atmosphere irradiance change of $1.1 \mathrm{~W} \mathrm{~m}^{-2}$ between the Maunder Minimum and the late 20th century, corresponding to a tropopause radiative forcing of $0.38 \mathrm{~W} / \mathrm{m}^{2}$ as in Shindell et al. (2006) and Wang et al. (2005). The model also includes the ozone photochemical response to solar irradiance variations, which is parameterized from the results of prior GISS modeling using a full atmospheric chemistry simulation (Shindell et al., 2006) for computational efficiency. The results from these millennial transient simulations and those from a second set, including doubled solar forcing magnitude performed to test the sensitivity of the climate response, were also presented by Mann et al. (2009) and by Pechony and Shindell (2010).

The GTAs $[\mathrm{G}-\mathrm{NH}]$ in the model were calculated using the average temperature of southern Greenland including the GISP2 site as the northern limit $\left(72^{\circ} 36^{\prime} \mathrm{N}, 38^{\circ} 30^{\prime} \mathrm{W}\right.$; $3200 \mathrm{~m}$ a.s.l.). The ensemble averages of the six $\mathrm{GTAs}_{[\mathrm{G}-\mathrm{NH}]}$ calculated with GISS-ER model were compared with the changes in solar irradiance (Fig. 7), and a similar correlation ( $r=-0.47$, ranging from $r=0.11$ to -0.75 in individual runs) to the observation was found between the $\mathrm{GTA}_{[\mathrm{G}-\mathrm{NH}]}$ and solar variability in the multidecadal-tocentennial timescale (e.g., 51-yr RMs; Fig. 7). The resampling test indicated a significant solar influence on the $\mathrm{GTA}_{[\mathrm{G}-\mathrm{NH}]}$ variation in the GISS-ER model in a $97 \%$ confidence level. We also tested the null hypothesis that the correlation between the $\mathrm{GTA}_{[\mathrm{G}-\mathrm{NH}]}$ and solar forcing in the model is a result of correlations between the $\mathrm{NH}$ temperature and the TSI. The null hypothesis was rejected for the $\mathrm{GTA}_{[\mathrm{G}-\mathrm{NH}]}$ in the GISS-ER simulation, indicating Greenland temperature negatively responded to changes in solar activity. Therefore, the observed $\mathrm{GTA}_{[\mathrm{G}-\mathrm{NH}]}$ variations, including the negative correlation between Greenland temperature and solar forcing, are physically explainable. This result is consistent with the results of earlier studies showing that the GISS simulation with integrated ozone feedback processes appears to properly reproduce many aspects of solar-induced NAO/AOlike dynamics (Mann et al., 2009).

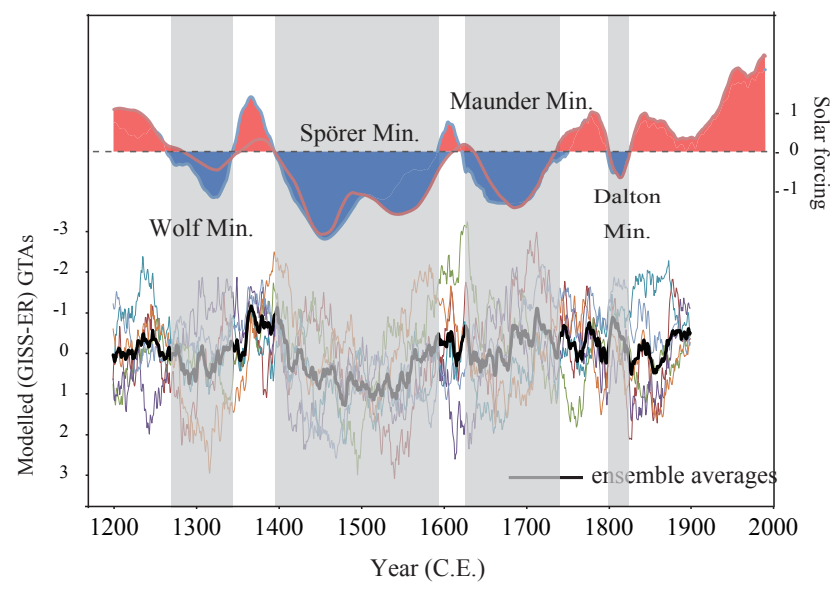

Fig. 7. Standardized solar variations (top panel) and $\mathrm{GTAs}_{[\mathrm{G}-\mathrm{NH}]}$ in the GISS-ER simulations (bottom panel). The solar variations and shaded areas are the same as in Fig. 3. Thin lines in the $\mathrm{GTAs}_{[\mathrm{G}-\mathrm{NH}]}$ represent each individual run, and the thick black line is the ensemble averages. Note that the y-axes for the $\operatorname{GTAs}_{[\mathrm{G}-\mathrm{NH}]}$ are reversed.

\section{Dynamic causes of solar-induced GTA $[\mathrm{G}-\mathrm{NH}]$ variation}

To investigate the spatial extent and mechanisms of solarinduced $\mathrm{GTA}_{[\mathrm{G}-\mathrm{NH}]}$ variations, we plotted the compositemean temperature differences of periods of stronger and weaker solar output, as defined in Fig. 3, for the model outputs and the grid proxy reconstruction of global temperatures (Mann et al., 2009) in Fig. 8. Importantly, the spatial features in the proxy map resemble the surface air temperature responses to the 11-yr solar cycles for the 1889-2006 period (Lean and Rind, 2008). The locations and extents of small areas of cooling in the northern North Atlantic are consistent in the two maps (Fig. 8). The cooling signal cannot be a result of the contamination of volcanic signals as large volcanic events were observed to cause positive NAOs and thus an in-phase relationship between the NH and Greenland temperatures. In addition, note that the temperatures in southern Greenland in the GISS-ER show cooler areas.

Earlier studies using the GISS-ER simulation and observations have shown that the NAO/AO-like temperature pattern is related to changes in large-scale dynamic atmospheric circulation (Lean and Rind, 2008) and polar night jets resulting primarily from solar spectral (UV) changes (Kodera and Kuroda, 2002; Kuroda and Kodera, 2002). Composite differences in the sea level pressure (SLP) in the GISS-ER model indicate significant pressure increases over both the Atlantic and Pacific sectors at mid-latitudes and decreases over the majority of the northern high latitudes (Fig. 9). Although the SLP anomalies show a more complex structure than the NAO and AO patterns and the signals are rather weak, these changes do project onto both of those variability modes and lead to altered flow from North America towards 

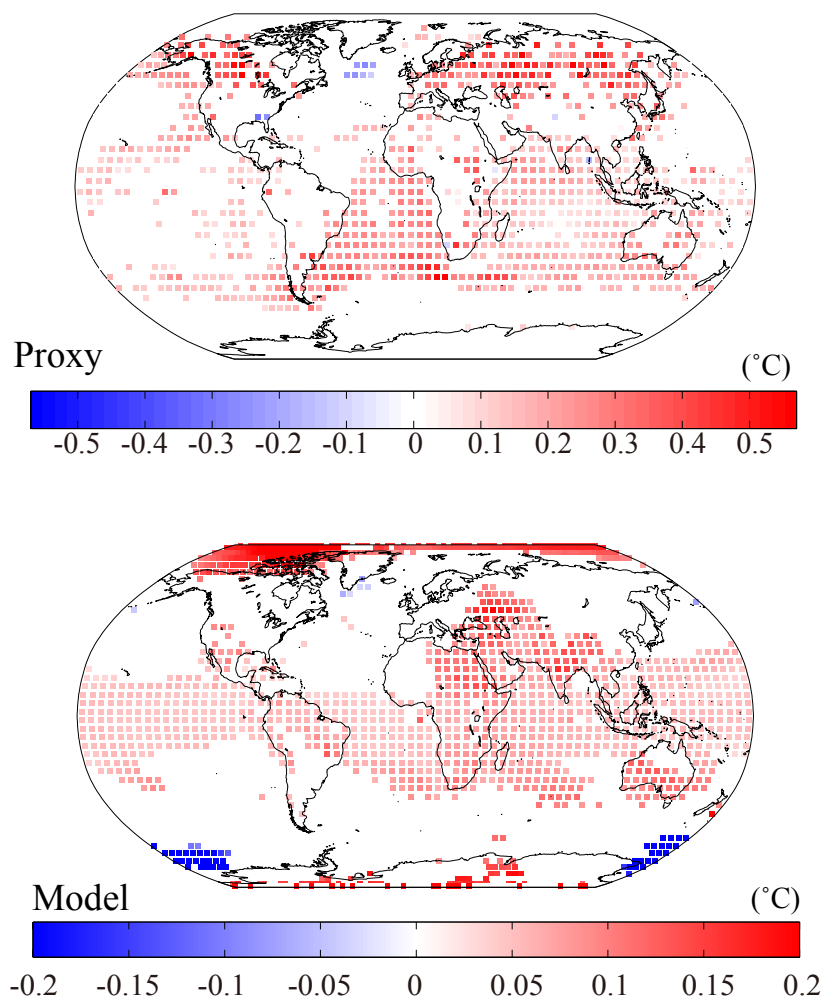

Fig. 8. Composite annual mean temperature differences (stronger solar output - weaker solar output) as defined in Fig. 3 from the model output (GISS-ER) and the proxy data (Mann et al., 2009). Only grids with $95 \%$ significance levels, calculated by re-sampling with two-sided tests as we do not have a priori knowledge on warmer or cooler responses to solar variations except in Greenland, are shown in color. For the GISS-ER (ensemble mean result), the solar forcing from the Maunder Minimum to the late 20th century is $0.38 \mathrm{~W} \mathrm{~m}^{-2}$.

Greenland and the North Atlantic, similar to that induced by NAO/AO anomalies (Fig. 9). As a result, Greenland experiences stronger northerly winds and resultant cooler temperatures. Earlier studies with GISS-ER and a previous version of GISS have shown that the solar-induced NAO/AO-like patterns are amplified by the interactive ozone processes in the atmosphere, which is called "top-down process" (Gray et al., 2010) as described previously (Shindell et al., 2001; Mann et al., 2009), and may also be linked to surface changes for instance in tropical and subtropical moisture convection processes through surface heating by variable solar activity (Shindell et al., 2001; Kodera, 2002; Kodera and Kuroda, 2002).

Regarding the observed centennial to multidecadal variations in $\mathrm{GTAs}_{[\mathrm{G}-\mathrm{NH}]}$, the mechanisms may involve oceanic processes (Cubasch et al., 1997; Waple et al., 2002) such as the Atlantic meridional overturning circulation (AMOC). To further investigate the dynamic causes of the $\mathrm{GTA}_{[\mathrm{G}-\mathrm{NH}]}$ variations, we investigated changes in the AMOC. The GISS-ER simulation exhibits a significant reduction of 0.3

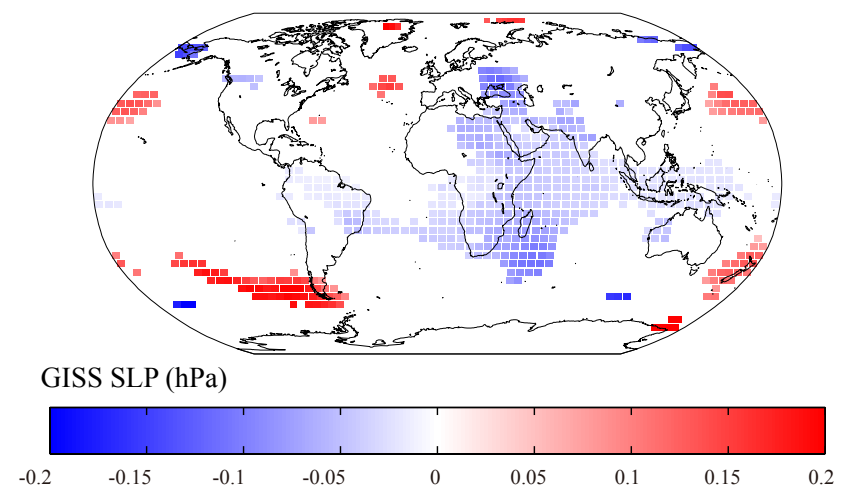

Fig. 9. Composite SLP differences in the GISS simulation (using the same data as in Fig. 8 except for the SLP). Grid data with $90 \%$ confidence levels, calculated by re-sampling (two-sided test), are shown in color.

$\pm 0.1 \mathrm{~Sv}$ from the mean value of $21.1 \mathrm{~Sv}$ in the AMOC (evaluated across $48^{\circ} \mathrm{N}$ at $900 \mathrm{~m}$ depth) as a difference between periods of stronger and weaker solar activity as defined above, thus indicating slowed heat transport from the South to the North Atlantic, which may explain part of the antiphase relationship between the NH and the southern Greenland temperatures. The same AMOC processes are often observed in model projections of future warming (Meehl et al., 2007). Owing to reduced AMOC in many models, northern North Atlantic areas including northern Europe are projected to experience less warming.

To further investigate the relationship between AMOC and GTA, we looked into a reconstructed North Atlantic average temperature record (Mann et al., 2009) over the past $800 \mathrm{yr}$ (Fig. 10). Greenland Summit temperatures exhibit significant correlation with average North Atlantic temperature over the observational period as in Fig. 4 in Kobashi et al. (2012) with a correlation coefficient of $r=0.58(p=0.03)$ in the annual time scale, and over the past $800 \mathrm{yr}$ (Fig. 10) with $r=0.60(p=0.09)$ in the multidecadal time scale. Multidecadal variation of average North Atlantic temperature, often called Atlantic multidecadal oscillation (AMO), has been linked with changes in AMOC variation and resultant interhemispheric heat transport in North Atlantic (Delworth and Mann, 2000; Knight et al., 2005; Otterå et al., 2010). We calculated North Atlantic temperature anomalies (NATAs) similar to GTA. It is found that NATAs possess similar characteristics with GTA $(r=0.5, p=0.18$, Fig. 10, bottom panel), indicating North Atlantic temperature was relatively warmer during the 15th century (at the time of lower solar activity during the Spörer Minimum) and cooler during the past few centuries (higher solar activity) than the $\mathrm{NH}$ temperature. We note that volcanic events may also have played an important role for the variation of NATA (Otterå et al., 2010), as more volcanic eruptions occurred during the lower solar activity over the past millennium. We speculate that, during lower (higher) solar activity, AMOC was stronger (weaker), and so 


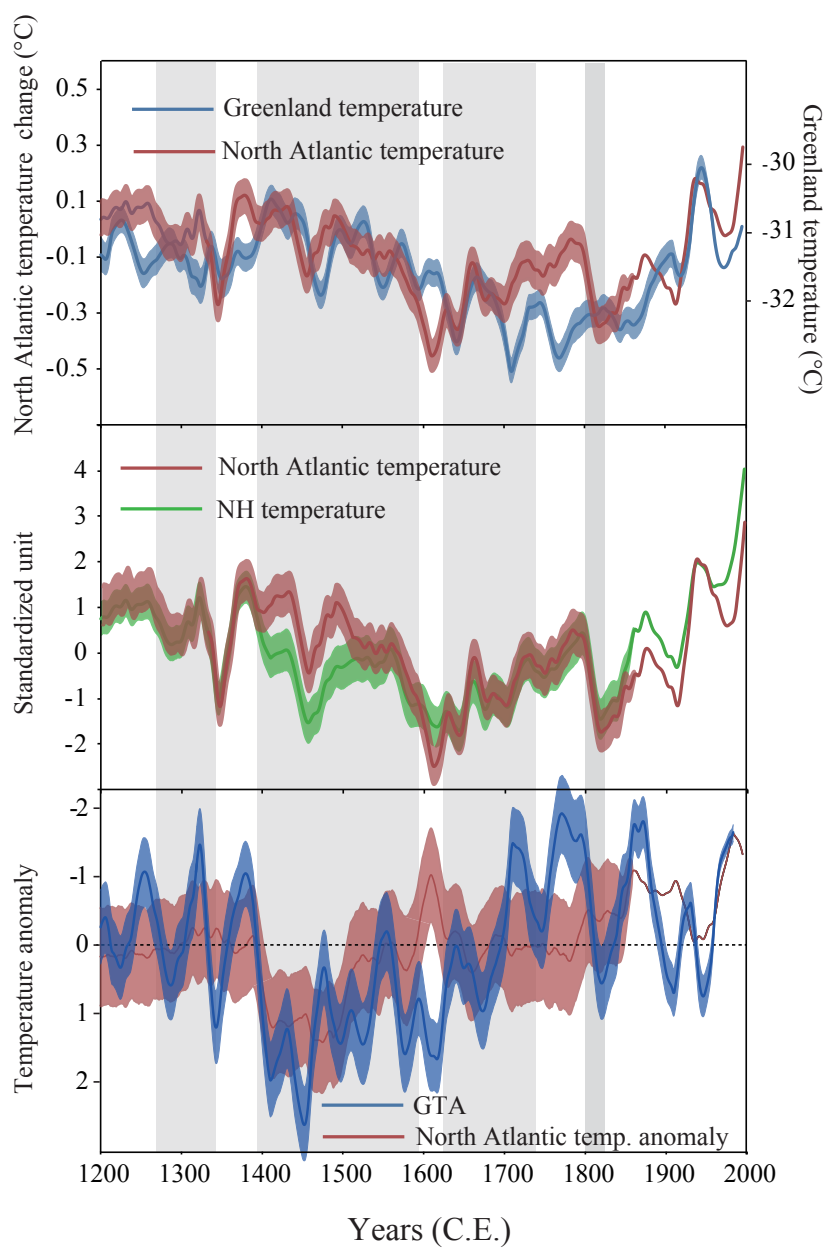

Fig. 10. Greenland and North Atlantic temperature anomalies over the past $800 \mathrm{yr}$. Top panel: Greenland temperature (Kobashi et al., 2010) and North Atlantic average temperature anomaly (Mann et al., 2009) in 21-yr RMs. Middle panel: standardized North Atlantic and NH average temperatures (Mann et al., 2009) in 21-yr RMs. Bottom panel: GTA (Mann NH) in 21-yr RMs is from Fig. 3c. North Atlantic temperature anomaly (NATA) was calculated by subtracting standardized $\mathrm{NH}$ temperature from standardized North Atlantic average temperature as in the middle panel. It is noted that Greenland temperature is significantly correlated with North Atlantic average temperature ( $r=0.60, p=0.09$ in $21-\mathrm{yr} \mathrm{RMs}$ ), while it is not with $\mathrm{NH}$ average temperature ( $r=0.43, p=0.21$ in 21 -yr RMs). Ninety-five percent confidence intervals $(2 \sigma)$ are estimated as for Fig. 3. Shaded areas represent periods of low solar activity same as in Fig. 3.

temperature was relatively higher (lower) in North Atlantic than the $\mathrm{NH}$ temperature over the past $800 \mathrm{yr}$. Therefore, the observed negative responses to solar variation in the northern North Atlantic (Greenland) suggest that oceanic responses to changes in solar outputs played a role in the $\mathrm{GTA}_{[\mathrm{G}-\mathrm{NH}]}$ variations.

\section{Conclusions}

Over the past $800 \mathrm{yr}$, Greenland temperature variability was dominated by background climate changes at the northern hemispheric scale, and these changes are known to be largely the result of solar and volcanic forcing prior to 1850 (Crowley, 2000). However, we find that the deviations in Greenland temperatures from that of the $\mathrm{NH}$ are also strongly influenced by atmospheric dynamics such as those produced by the NAO/AO, in which longer-term variations are induced by atmospheric circulation responses to variations in solar outputs, with an additional contribution from the oceanic response. This finding indicates that the Greenland temperature minimum over the past $800 \mathrm{yr}$ occurred in the early 18 th century, in contrast to the minimum for the $\mathrm{NH}$ temperature in the 15-16th century (Figs. 3 and 6) - likely because of increased solar forcing during the 18th century. In addition, during the latter half of the 20th century, at time of high solar activity, Greenland temperature exhibited less pronounced warming than the $\mathrm{NH}$. If future solar activity were to be low compared with that of the past $100 \mathrm{yr}$ (Livingston and Penn, 2009), it may reveal a hidden warming of Greenland caused by increasing greenhouse gases during the latter half of the 20 th century.

Acknowledgements. We appreciate the in-depth discussion with M. Yoshimori and A. Abe-Ouchi. We thank B. Vinther and R. Keeling for useful discussion and J. Okuno for help creating the figures in earlier manuscripts. T. K. appreciates the continued support of J. Severinghaus with the temperature reconstruction. D. S. acknowledges NASA MAP and LWS, and computational resources provided by the NASA High-End Computing Program through the NASA Center for Climate Simulation at Goddard Space Flight Center. This project is supported by KAKENHI 23710020. The production of this paper was supported by an NIPR publication subsidy.

Edited by: C. Barbante

\section{References}

Bard, E., Raisbeck, G. M., Yiou, F., and Jouzel, J.: Solar modulation of cosmogenic nuclide production over the last millennium: comparison between ${ }^{14} \mathrm{C}$ and ${ }^{10} \mathrm{Be}$ records, Earth Planet. Sc. Lett., 150, 453-462, 1997.

Bard, E., Raisbeck, G., Yiou, F., and Jouzel, J.: Solar irradiance during the last 1200 years based on cosmogenic nuclides, Tellus B, 52, 985-992, 2000.

Bard, E., Raisbeck, G. M., Yiou, F., and Jouzel, J.: Comment on "Solar activity during the last $1000 \mathrm{yr}$ inferred from radionuclide records" by Muscheler et al. (2007), Quaternary Sci. Rev., 26, 2301-2304, 2007.

Barriopedro, D., García-Herrera, R., and Huth, R.: Solar modulation of Northern Hemisphere winter blocking, J. Geophys. Res., 113, D14118, doi:10.1029/2008JD009789, 2008. 
Bjørk, A. A., Kjær, K. H., Korsgaard, N. J., Khan, S. A., Kjeldsen, K. K., Andresen, C. S., Box, J. E., Larsen, N. K., and Funder, S.: An aerial view of 80 years of climate-related glacier fluctuations in southeast Greenland, Nat. Geosci., 5, 427-432, doi:10.1038/NGEO1481, 2012.

Box, J. E.: Survey of Greenland instrumental temperature records: 1873-2001, Int. J. Climatol., 22, 1829-1847, 2002.

Box, J. E., Yang, L., Bromwich, D. H., and Bai, L. S.: Greenland Ice Sheet Surface Air Temperature Variability: 1840-2007, J. Climate, 22, 4029-4049, 2009.

Brohan, P., Kennedy, J., Harris, I., Tett, S., and Jones, P.: Uncertainty estimates in regional and global observed temperature changes: a new dataset from 1850, J. Geophys. Res, 111, D12106, doi:10.1029/2005JD006548, 2006.

Cappelen, J.: DMI monthly Climate Data Collection 1768-2010, Denmark, The Faroe Islands and Greenland, 54 pp., 2011.

Crowley, T. J.: Causes of climate change over the past 1000 years, Science, 289, 270-277, 2000.

Cubasch, U., Voss, R., Hegerl, G., Waszkewitz, J., and Crowley, T.: Simulation of the influence of solar radiation variations on the global climate with an ocean-atmosphere general circulation model, Clim. Dynam., 13, 757-767, 1997.

Delaygue, G. and Bard, E.: Solar forcing based on ${ }^{10} \mathrm{Be}$ in Antarctica ice over the past millennium and beyond, in: Geophysical Research Abstracts, EGU General Assembly 2009, EGU20096943, 2009.

Delworth, T. L. and Mann, M. E.: Observed and simulated multidecadal variability in the Northern Hemisphere, Clim. Dynam., 16, 661-676, 2000.

Gao, C., Robock, A., and Ammann, C.: Volcanic forcing of climate over the past 1500 years: An improved ice core-based index for climate models, J. Geophys. Res.-Atmos., 113, D23111, doi:10.1029/2008JD010239, 2008.

Gray, L., Beer, J., Geller, M., Haigh, J., Lockwood, M., Matthes, K., Cubasch, U., Fleitmann, D., Harrison, G., and Hood, L.: Solar influences on climate, Rev. Geophys., 48, G4001, doi:10.1029/2009RG000282, 2010.

Grinsted, A., Moore, J. C., and Jevrejeva, S.: Application of the cross wavelet transform and wavelet coherence to geophysical time series, Nonlin. Processes Geophys., 11, 561-566, doi:10.5194/npg-11-561-2004, 2004.

Häkkinen, S., Rhines, P. B., and Worthen, D. L.: Atmospheric Blocking and Atlantic Multidecadal Ocean Variability, Science, 334, 655-659, 2011.

Haigh, J. D.: A GCM study of climate change in response to the 11year solar cycle, Q. J. Roy. Meteorol. Soc., 125, 871-892, 1999.

Hanna, E. and Cappelen, J.: Recent cooling in coastal southern Greenland and relation with the North Atlantic Oscillation, Geophys. Res. Lett., 30, 1132, doi:10.1029/2002GL015797, 2003.

Hurrell, J. W.: Decadal trends in the North Atlantic Oscillation: regional temperatures and precipitation, Science, 269, 676-679, 1995.

Hurrell, J. W.: Influence of variations in extratropical wintertime teleconnections on Northern Hemisphere temperature, Geophys. Res. Lett., 23, 665-668, 1996.

Ineson, S., Scaife, A. A., Knight, J. R., Manners, J. C., Dunstone, N. J., Gray, L. J., and Haigh, J. D.: Solar forcing of winter climate variability in the Northern Hemisphere, Nat. Geosci., 4, 753-757, 2011.
Ito, H. and Minobe, S.: Data analysis for meteorology and physical oceanography, Meteorological Research Note 233, Meteorological Society of Japan, Tokyo, 263 pp., 2010.

Jones, P., Jonsson, T., and Wheeler, D.: Extension to the North Atlantic Oscillation using early instrumental pressure observations from Gibraltar and south-west Iceland, Int. J. Climatol., 17, 1433-1450, 1997.

Knight, J. R., Allan, R. J., Folland, C. K., Vellinga, M., and Mann, M. E.: A signature of persistent natural thermohaline circulation cycles in observed climate, Geophys. Res. Lett., 32, L20708, doi:10.1029/2005GL024233, 2005.

Kobashi, T., Severinghaus, J. P., Barnola, J. M., Kawamura, K., Carter, T., and Nakaegawa, T.: Persistent multi-decadal Greenland temperature fluctuation through the last millennium, Climatic Change, 100, 733-756, 2010.

Kobashi, T., Kawamura, K., Severinghaus, J. P., Barnola, J.-M., Nakaegawa, T., Vinther, B. M., Johnsen, S. J., and Box, J. E.: High variability of Greenland surface temperature over the past 4000 years estimated from trapped air in an ice core, Geophys. Res. Lett., 38, L21501, doi:10.1029/2011GL049444, 2011.

Kobashi, T., Kawamura, K., Goto-Azuma, K., Box, J. E., Gao, C.C., and Nakaegawa, T.: Causes of Greenland temperature variability over the past $4000 \mathrm{yr}$ : implications for northern hemispheric temperature change, Clim. Past Discuss., 8, 4817-4883, doi:10.5194/cpd-8-4817-2012, 2012.

Kodera, K.: Solar cycle modulation of the North Atlantic Oscillation- Implication in the spatial structure of the NAO, Geophys. Res. Lett., 29, 59-51, 2002.

Kodera, K. and Kuroda, Y.: Dynamical response to the solar cycle, J. Geophys. Res., 107, 4749, doi:10.1029/2002JD002224, 2002.

Korte, M. and Constable, C.: The geomagnetic dipole moment over the last 7000 years-new results from a global model, Earth Planet. Sc. Lett., 236, 348-358, 2005.

Kuroda, Y. and Kodera, K.: Effect of solar activity on the polar-night jet oscillation in the northern and southern hemisphere winter, J. Meteorol. Soc. Jpn., 80, 973-984, 2002.

Lean, J. and Rind, D.: How natural and anthropogenic influences alter global and regional surface temperatures: 1889 to 2006 , Geophys. Res. Lett., 35, L18701, doi:10.1029/2008GL034864, 2008.

Lean, J., Beer, J., and Bradley, R.: Reconstruction of solar irradiance since 1610: Implications for climate change, Geophys. Res. Lett., 22, 3195-3198, 1995.

Livingston, W. and Penn, M.: Are sunspots different during this solar minimum?, EOS, 90, 2009.

Mann, M. E., Zhang, Z., Rutherford, S., Bradley, R. S., Hughes, M. K., Shindell, D., Ammann, C., Faluvegi, G., and Ni, F.: Global signatures and dynamical origins of the Little Ice Age and Medieval Climate Anomaly, Science, 326, 1256-1260, 2009.

Meehl, G. A., Stocker, T. F., Collins, W. D., Friedlingstein, P., Gaye, A. T., Gregory, J. M., Kitoh, A., Knutti, R., Murphy, J. M., Noda, A., Raper, C. B., Watterson, I. G., Weaver, A. J., and Zhao, Z.-C.: Global climate projections, in: Climate change 2007: the physical science basis; Working Group I, contribution to the Fourth Assessment Report of the Intergovernmental Panel on Climate Change, Cambridge University Press, Cambridge, 747-845, 2007. 
Moberg, A., Sonechkin, D. M., Holmgren, K., Datsenko, N. M., and Karlen, W.: Highly variable Northern Hemisphere temperatures reconstructed from low- and high-resolution proxy data, Nature, 433, 613-617, 2005.

Osborn, T. J.: Winter 2009/2010 temperatures and a record-breaking North Atlantic Oscillation index, Weather, 66, 19-21, 2011.

Otterå, O. H., Bentsen, M., Drange, H., and Suo, L.: External forcing as a metronome for Atlantic multidecadal variability, Nat. Geosci., 3, 688-694, 2010.

Pechony, O. and Shindell, D.: Driving forces of global wildfires over the past millennium and the forthcoming century, P. Natl. Acad. Sci., 107, 19167-19170, 2010.

Rimbu, N. and Lohmann, G.: Winter and summer blocking variability in the North Atlantic region - evidence from long-term observational and proxy data from southwestern Greenland, Clim. Past, 7, 543-555, doi:10.5194/cp-7-543-2011, 2011.

Schmidt, G. A., Ruedy, R., Hansen, J. E., Aleinov, I., Bell, N., Bauer, M., Bauer, S., Cairns, B., Canuto, V., and Cheng, Y.: Present-day atmospheric simulations using GISS ModelE: Comparison to in situ, satellite, and reanalysis data, J. Climate, 19, 153-192, 2006.

Shindell, D. T., Schmidt, G. A., Mann, M. E., Rind, D., and Waple, A.: Solar forcing of regional climate change during the Maunder Minimum, Science, 294, 2149-2152, 2001.

Shindell, D. T., Faluvegi, G., Miller, R. L., Schmidt, G. A., Hansen, J. E., and Sun, S.: Solar and anthropogenic forcing of tropical hydrology, Geophys. Res. Lett, 33, L24706, doi:10.1029/2006GL027468, 2006.
Steinhilber, F., Beer, J., and Frlich, C.: Total solar irradiance during the Holocene, Geophys. Res. Lett., 36, L19704, doi:10.1029/2009GL040142, 2009.

Trouet, V., Esper, J., Graham, N. E., Baker, A., Scourse, J. D., and Frank, D. C.: Persistent positive North Atlantic Oscillation mode dominated the medieval climate anomaly, Science, 324, 78-80, 2009.

Vinther, B. M., Johnsen, S. J., Andersen, K. K., Clausen, H. B., and Hansen, A. W.: NAO signal recorded in the stable isotopes of Greenland ice cores, Geophys. Res. Lett, 30, 1387, doi:10.1029/2002GL016193, 2003.

Vinther, B. M., Jones, P. D., Briffa, K. R., Clausen, H. B., Andersen, K. K., DahlJensen, D., and Johnsen, S. J.: Climatic signals in multiple highly resolved stable isotope records from Greenland, Quarternary Sci. Rev., 29, 522-538, 2010.

Wang, Y. M., Lean, J., and Sheeley Jr, N.: Modeling the sun's magnetic field and irradiance since 1713, Astrophys. J., 625, 522538, 2005.

Wanner, H., Brönnimann, S., Casty, C., Gyalistras, D., Luterbacher, J., Schmutz, C., Stephenson, D. B., and Xoplaki, E.: North Atlantic Oscillation-concepts and studies, Surv. Geophys., 22, 321-381, 2001.

Waple, A., Mann, M., and Bradley, R.: Long-term patterns of solar irradiance forcing in model experiments and proxy based surface temperature reconstructions, Clim. Dynam., 18, 563-578, 2002.

Woollings, T., Lockwood, M., Masato, G., Bell, C., and Gray, L.: Enhanced signature of solar variability in Eurasian winter climate, Geophys. Res. Lett., 37, L20805, doi:10.1029/2010GL044601, 2010. 